\title{
Smartphone addiction and its multifunctional concerns for teachers in academic classrooms
}

\author{
Alireza Atarodi ${ }^{*}$ and Ahmadreza Atarodi ${ }^{2}$ \\ ${ }^{1}$ Department of Knowledge and Information Science, Paramedical College and Social Development \& Health Promotion Research Center, Gonabad University of \\ Medical Sciences, Gonabad, Iran \\ ${ }^{2}$ School of Medicine, Student Research Committee, Gonabad University of Medical Sciences, Gonabad, Iran
}

\section{Letter to editor}

More technological the societies become, more concern follows. The concerns raid the population in relation with technology directly or indirectly. No way out, some must be accepted, tolerated and or admitted mandatorily. I am a teacher lecturing and teaching in a $3^{\text {rd }}$ world country full of some technologies of varieties imported from overseas or made locally with so many positive and negative impacts, a useful applicants although presenting negative aspects as well. A teacher, not me alone, through the world entering the class with so many stresses, concerns and anxiety of misusing of the students the new tools badly and to be physically in the class but not with you and your academic lecture from the bottom of their heart and feeling as a need. They are well busy with their smartphone in chat, online gaming, surfing the web, internet and different social media or they are forming a future promise with other guys. They, I mean the student, are glancing the screen from the first to the end, sometimes or more under the desk. A teacher is a responsible one for them to make and teach them living, morality, the way they should be in the future and hesitate to stop them directly in the class misusing since a teacher dignity allows him not to wreck down his/her students' personality. Then it is a chaotic and problematic status in the world that we all are somehow faced with. In a research in India for example it showed that almost half $(44 \%)$ of the samples of a research reported severely dependent levels of internet addiction. Some who used higher levels of internet addiction were reported with depressive disorders. They claimed that internet use could be both beneficial and problematic and could make addiction resulting social isolation, anxiety, stress and mental health disorders. As the said research showed: the prevalence of internet was reported $8 \%$ in college populations, and $9.5 \%$ of internet addiction among medical college students [1]. However, some examples of positive applications of information technology mostly in HIT field (health information technology) such as, storage, management, share, analysis and transmission of health data and information including electronic and personal health record systems containing patientspecific data that can be accessed by patients and professionals (data sharing) for clinical, administrative and/or personal (patient-specific) purposes through smartphones today, should not be neglected, but so many concerns is left in need to find a way out [2].

Smartphone is so handy and used for people to perform their daily as well as their professional activities, to access information and knowledge from the internet, using it in classrooms and lectures. In fact, some students capture the teachers lecture notes or other notes showing it to become a learning aid in class [3]. In Brunei next with $87 \%$ of the students used it for listening to music or video/movie streaming, and social networks, online learning (67\%), and browsing e-news or e-book with 55\%. Then the researchers claim that smartphone can also create a serious disturbance during lectures if students play with their smartphones instead of paying attention to lectures. The problems of misusing it among students in class were also reported by a number of studies and argued that it was more as distractions in the classroom rather than learning aids. If they are asked to put them away, silent or off, no satisfaction status is shown since it is more designed for entertainment and pleasure purposes with some soft wares installed. Therefore, teachers may think that smartphones may cause learning interference and be problematic rather than learning support. Some researches support the argument that smartphones are interferences in learning process and this leads us to the question that is smartphones a better learning tool or learning interference? [4].

A survey also conducted by Tavakolizadeh and collogues on mobile addiction showed that $35.5 \%$ of the college students had a normal mental health status and $64.5 \%$ had an abnormal status. The results of the subscales of the questionnaire (GHQ-28) showed that many of the students (89.1\%) manifested social dysfunction symptoms, while $29.7 \%$ of them reported symptoms of depression. Somatization and anxiety among the students have been also reported $52.4 \%$ and $48.3 \%$ respectively. Based on the results, 443 students (63.3\%) used mobile phone normally, while 257 students $(36.7 \%)$ had used mobile phone excessively not the way it should be [5].

Now, we shouldn't hate new technology illogically and throw it away and not do embrace it additionally. The best and logic way is to use it in a right way, right time, right aim, and right user in right place, however we should put this into account that we as teachers, families, medias and the societies must and should make them understand, teach, learn and advise them for positively using of new tools and technologies such as smartphones mostly in academic fields, because we are asked for its valuable situation and expectations running over there. We need a better world with a better technologies, I believe all believe it, presenting well-being and welfare and a healthy life, since health can make wealth. Technology can help...! Be such so, I hope.

${ }^{\star}$ Correspondence to: Alireza Atarodi, Department of Knowledge and Information Science, Paramedical College and Social Development \& Health Promotion Research Center, Gonabad University of Medical Sciences, Gonabad, Iran, E-mail: aratarodi1387@yahoo.com

Received: May 05, 2019; Accepted: June 26, 2019; Published: June 28, 2019 


\section{References}

1. Nisbin AK, Sharma MK, Hallford DJ (2019) Internet addiction among Indian helpseeking patients with mental health disorders. Ment Health Addic Res p. 4.

2. Atarodi A, Atarodi A (2019) The impact of information technology on health. $J$ Research \& Health 9: 193- 194.

3. Anshari M, Alas Y, Yunus NM, Sabtu NI, Hamid MS (2016) Online learning: trends, issues, and challenges in big data era. Journal of E-Learning and Knowledge Society 12: 121-134.
4. Anshari M, Almunawar MN, Shahrill M, Wicaksono DK, Huda M (2017) Smartphones usage in the classrooms: Learning aid or interference? Educ Inf Technol 22: 3063-3079.

5. Tavakolizadeh J, Atarodi A, Ahmadpour S, Pourgheisar A (2014) The prevalence of excessive mobile phone use and its relation with mental health status and demographic factors among the students of Gonabad University of medical sciences in $2011-2012$. Razavi Int J Med 2: e15527.

Copyright: (C2019 Atarodi A. This is an open-access article distributed under the terms of the Creative Commons Attribution License, which permits unrestricted use, distribution, and reproduction in any medium, provided the original author and source are credited. 